\title{
The initial stage of the international sojourn: excitement or culture shock?
}

\begin{abstract}
This paper presents findings from an ethnographic study of the adjustment journey of international postgraduate students at a university in the South of England, which involved interviews and participant observation over a twelve-month academic year. It was discovered that the initial stage of the sojourn was not characterized by feelings of excitement, as suggested by the U-Curve model (and its successors): though such feelings were present, they were overwhelmed by negative symptoms more commonly associated with culture shock. The implications of these findings for support structures in Higher Education are discussed.
\end{abstract}

\section{Key words:}

International students adjustment first stage

Excitement $\quad$ culture shock Support 


\section{Introduction}

The relationship between income generation and overseas recruitment in Higher Education has been well documented (Ryan and Carroll 2005), with the US, Australia and the UK being the most popular destinations for international students. In the UK, international students make up $16 \%$ of the total British student population, and represent almost a third of universities' total fees income (MacLeod 2006). Increasing overseas recruitment is the target of most universities (Ryan and Carroll 2005), and in the UK, this has been encouraged by the Prime Minister’s Initiative 2006, which has urged British universities to extend recruitment to 100,000 more international students by 2011.

Accompanying the steady rise in the number of international students in global HE has been a growth in the research dedicated to the international sojourn ${ }^{1}$, with adjustment being one of several interests (Ward 2001). Given the economic dependence of universities on the fees from international students, it is important that there is a clear understanding of the issues facing them if an optimum service is to be delivered (Ryan 2005). This is seen as not only the moral duty of institutions seeking to attract full-paying students, but it will also result in improved student retention, positive word of mouth and therefore more successful recruitment (Allen and Higgins 1994; Smith 2006).

The move to a new environment is cited as one of the most traumatic events in a person's life as in most sojourners some degree of culture shock is inevitable (Hamburg and Adams 1967; Kim 1988; Berry 1994). Culture shock is defined as anxiety that results from losing the familiar signs and symbols of social intercourse, and their substitution by other cues that are strange (Hall 1959;

\footnotetext{
${ }^{1}$ The term sojourn is used by Ward et al. (2001) to refer to temporary between-society culture contact.
} 
Oberg 1960). It is likened by many writers to a period of mourning for the home world, characterized by feelings of grief and separation anxiety (Bock 1970; Garza-Guerro 1974; Furnham and Bochner 1986; Furnham 1997). Whilst an institution cannot completely offset all associated symptoms (Torbiorn 1994), awareness of the painful adjustment journey often made by international students may inform the provision of institutional support (Louie 2005; Ryan 2005).

There is, however, limited consensus and clarity as to what adjustment means, as the construct has been described and measured in varying ways and from several perspectives and various models have been put forward (Ward and Kennedy 1999). Additionally, there is some confusion in the literature on transition as to exactly when the stage of culture shock takes place. In Lysgaard's (1955) model, adjustment seems to follow a U-shaped curve; the first stage is characterized by positive feelings; this is followed by a stage of maladjustment; and finally adjustment is reached. In Oberg's model (1960), adjustment is grouped into four stages: a first Honeymoon stage of fascination; a second Crisis stage of hostility and aggression; by the third Recovery stage the visitor feels more used to the new cultural environment and develops a sense of humour; and in the fourth Adjustment stage, adjustment is complete. In the W-curve model put forward by Gullahorn and Gullahorn (1963), the $\mathrm{U}$ is extended to a $\mathrm{W}$, to take account of the $\mathrm{U}$-shaped readjustment journey made by sojourners once they return home. Many writers have elaborated the U-curve model, for example, Brown's acculturation model (1980) incorporates the four stages of excitement and euphoria; culture shock (loneliness, estrangement, sadness, hostility, homesickness, physical illness); culture stress (partial recovery); and adaptation. Similarly, Adler’s model of transitional experience (1975) delineates five phases: contact (excitement and awareness of cultural dissimilarities); disintegration (denoting a period of confusion and disorientation); reintegration (a 
strong rejection of the new culture and a seeking out of co-nationals); autonomy (understanding of the new culture); independence (cultural relativism achieved). Torbiorn’s (1994) first stage of fascination is followed by a period of culture shock: after a few months, feelings become more positive, and satisfaction increases; towards the end of the first year, subjective adjustment is reached. Similarly, Mohamed's model (1997) identifies four stages: orientation and autonomy (learning new skills); transitions of self-worth (stress and ambivalence between complying with and resisting new demands); consolidation of role identity (awareness of various systems); competence and integrative maturity (development of hope and confidence). In a few models, a time frame for each stage is suggested, but this is absent in most.

What such models have in common is the depiction of the first stage as a time of excitement and a positive frame of mind (Thomas and Harrell 1994; Ward et al. 2001). It is argued however that there is little empirical evidence of this early euphoria (Searle and Ward 1990). Transition is better understood as a process of change that is especially stressful at first, with problems being the greatest upon arrival and stress decreasing as a function of various variables (Biddle 1979; Furnham 1995; Ward 2001). Nevertheless, Furnham and Erdmann (1995) point out that it is important to distinguish between psychological and sociocultural adjustment, which are predicted and explained by different variables and follow distinctly variable patterns (Searle and Ward 1990; Furnham and Erdmann, 1995). Such a distinction may have important implications for those offering pastoral support to international students, informing for example the way counsellors relate to the various aspects of the adjustment experience. It may be appropriate at times to recommend an informational, culture learning approach, as advocated by Furnham and Bochner (1986), focusing on the acquisition of appropriate behaviour and skills; however, this might be an inappropriate course of action for a counsellor facing a student who is suffering low self-esteem or depression. Inaccurate understanding of what comprises the initial stage of the 
sojourn could have serious consequences for the counselling services offered to newly-arrived students.

This study aims to contribute to our understanding of what comprises adjustment, using the experience of a group of international postgraduate students to describe and define the initial stage of the sojourn. It is hoped that understanding of the common challenges faced by sojourners will help to improve the service offered by those dealing with international students, including personal tutors, programme administrators, lecturers and counsellors. Findings are taken from a study of the year-long adjustment journey made by international students at a university in the South of England. After presenting students' preoccupation in the initial few weeks (the first interview took place either during induction week or in the first week of term, just after students’ arrival in England), the applicability of the models of adjustment will be considered: does students' experience fit in with the notion that the first stage of the sojourn is characterised by feelings of euphoria or fascination (Lysgaard 1955; Oberg 1960) or is it during the first stage when most distress is experienced (Ward et al. 2001)? There is little indication in many adjustment models as to how long each stage of the sojourn lasts, but in this study, the first stage refers to the first few weeks of the academic year 2003.

\section{Methodology}

The aim of the study was to obtain the insider perspective on the adaptation process, an aim best fulfilled by the ethnographic approach which offered the opportunity to study students in the natural setting over a long period using the twin methods of participant observation and in-depth interviews that characterize ethnography (Fetterman 1998). The setting chosen for this research was the Graduate School at a university in the south of England, as the main researcher (L.B.) 
works there as a lecturer in English for Academic Purposes (EAP), and is already 'in the field'; she had direct access to students and ample opportunity for observation in an overt participant role. She did not mark students' work and had no input in assessment, and this was important when considering ethical issues. Of the 150 postgraduate international students in the School, the majority were from South East Asia, reflecting the most common source of international students for UK universities (UKCOSA 2006); around a third were from Europe, Africa and the Middle East.

Ethical approval to undertake this study was sought from the university’s Research Ethics Committee, and informed consent was obtained to observe and record observations on a daily basis; all students were assured of confidentiality and anonymity. In addition, thirteen students from thirteen different nations volunteered to be interviewed at regular intervals over a 12 month academic year (each pre-arranged, tape-recorded interview normally lasted two hours). Although no individual can represent an entire culture, culture clearly has a defining impact on an individual's make-up (Hofstede 1991), meaning that there would be access to experience of the sojourn from many different perspectives. The interviewee profile offered below should help the reader to locate the various personalities referred to in the paper (please note that pseudonyms are used). These interviews were complemented and enriched by the many conversations that took place outside these formally arranged times. Ethnography is initially inductive (Fetterman 1998), therefore the first interview with students was informal and unstructured, and as advised by Spradley (1979), grand tour questions were used to stimulate conversation. Subsequent interviews were guided by the topics and concepts that had emerged in previous interviews, indeed new ideas and themes emerged throughout the academic year.

\section{Table 1: Interviewee Profile}


Olga, female, Russian, 22, single.

Kyoung, female, Korean, 40, Buddhist, married with two children.

Natalia, female, Slovenian, 32, cohabiting.

Xia, female, Taiwanese, 33, married.

Brigitte, female, German, 26, single.

Antonio, male, Brazilian, 30, single.

Mohamed, male, Jordanian, 26, single.

Ning, female, Chinese, 28, single.

Paranee, female, Thai, 28, single.

Rini, female, Indonesian, 27, single.

Panya, female, Malaysian, 22, single.

Kiana, female, Iranian, 32, married with one child.

Cecilia, female, South African, 34, married with two children.

The decision to study an institution at a particular time is significant. Students have particularly intense emotional experiences at the start of term when they would be attempting to adapt not only to a new sociocultural environment but also to unfamiliar academic situations. Thus both interviews and observations started at the beginning of the year, countering the criticism often made of studies of adjustment, that they are hampered by sojourners’ retrospective accounts (Church 1982; Ward 2001). The reader will notice that students used the past tense to refer to the days leading up to the first interview, and used the present tense to describe feelings that were ongoing. Data collection was completed at the end of the academic year, which meant that their total academic experience was captured. 
In addition to formal interviewing, participant observation was conducted throughout the year, so that the experience of the whole cohort of 150 students was taken into account. Being a participant observer involves not only watching a scene but also participating in it and recording events and conversations as they occur (Hammersley and Atkinson 1995). Examples of observation sites included: the classroom, the corridor, the library, the coffee bar, the canteen, the office, induction, social events organised by the School or University and by students themselves.

After the first interviews had been conducted in the first weeks of term and observation had begun, preliminary analysis, involving coding field and interview data, was carried out. Coding meant reading through notes and repeatedly listening to tapes and reading transcripts until themes or categories began to emerge, as certain phrases events, activities, ideas etc occurred repeatedly in the text. Transcripts, field notes and email correspondence were scrutinised, and recurring topics were highlighted to be followed up further interview. The major themes of this doctoral study were: language difficulties, academic challenges, social interaction, identity, food habits and changes in the self.

With regard to the generalisability of findings, it is acknowledged that a small interviewee sample and the selection of one case will make it difficult to move to general classifications. Nevertheless, ethnographers often feel that similar settings are likely to produce similar data, and that theory-based generalisation can be achieved, involving the transfer of theoretical concepts found from one situation to other settings and conditions (Daymon and Holloway 2002). The setting for this research was chosen for the researcher's ability to transfer the findings to similar settings, i.e. Higher Education institutions in the UK that recruit international postgraduate students, and also to similar 
actors, i.e. international postgraduates on a one-year intensive Masters programme. It is possible to infer that such students may well face a similar experience to students in this study, with modifications according to differing external circumstances and personality differences. The review of the literature on adjustment reflects many of this study's findings, and point to a common experience among international sojourners. The present paper aims to convey the individual insider experience of this commonly documented picture.

\section{Main Findings}

\section{Feeling nervous}

Reflecting a nervous state of mind, which is common in the first stage of the sojourn (Storti 1990), the following words were found repeatedly in the first interview transcripts to describe how students felt in the days following arrival in England: scared, frightened, unsure, nervous, anxious, stressed, and uncertain.

Cecilia summed up the feeling: I was very nervous, nervous of the unknown.

As Lord and Dawson's study (2002) found, interviewees' nerves centred on the arrival at the airport, travelling to the university town and greeting either the host family or university accommodation staff. For example, Xia was apprehensive about speaking in English for the first time at the airport with native speakers: 
I'm a little afraid to come in the airport. It's very crowded, and every people looks very tired, and rushed. I'm nervous because they speak so quick. And so I have to ask them to speak slowly. Slower than their usual.

Interviewees were particularly anxious about finding the right transport from the airport to the university town, as Rini explained:

Yeah, I was little bit nervous. Oh my god! I don't know how to catch the coach! 'How can I get that?' I try. I went to coach station. I was a little bit nervous, a little bit confused because, ‘where is it?' I mean I don't know England at all because I haven't been here before, that's why.

Cecilia said that her nerves didn't abate until she had arrived in the host town, in case she caught the wrong train:

I was nervous because I was not sure even when I was on the train. I was not sure it was the right one, whether I was going where I want to go, whether I am lost. Oh, the country, strange country.

As Giddens (1991) states, anxiety is never far away in people, it only takes the arrival at a foreign airport for them to become unsettled. Out of their normal routine, sojourners are often plunged into 'terror in face of the uncanny' (Bruner 1956). As one might expect, such anxiety was stirred up every time a new situation presented itself, and though it abated as time passed, this was a prevalent feeling in the first weeks of term, particularly with regard to speaking in English. Students were extremely anxious in the first few weeks about their academic and general linguistic competence, confirming the preoccupation with language identified in other studies 
(e.g. Persaud 1993). The vocabulary used repeatedly by students to refer to English language ability included words such as nervous, scared, embarrassed, ashamed, not confident, frightened, panic, confused and shy, confirming the association in the literature between foreign language use and fear, distress, anxiety and shame (e.g. Kim 1988; Giddens 1991; Storti 1990; Kramsch 1993). A common reaction to the new language was panic, as Mohamed's exclamation shows:

Oh my God! Everything is in English, so you need to translate, to think, 'what does that mean?' Yeah, the first days the shock was the different language because you know I speak Arabic and I came to a different language, it was awful!

Self-doubt and loss of self-esteem are typical feelings among sojourners as they struggle to make themselves understood in the first few weeks (Hofstede 1991). Anxiety over language was not confined to those interviewed, as during induction week, observation showed that the majority of students often seemed anxious when speaking in English and entry after entry in the field journal in the first few weeks concerned students' preoccupation with their linguistic competence, or lack thereof. This anxiety was intense and lasted many weeks, its lessening being a function of the development of some communicative fitness, reflecting the link between time and adjustment (Torbiorn 1994).

\section{Feeling adrift}

Many students confessed to feeling confused when faced with unfamiliar physical surroundings (both on and off campus), and unfamiliar conventions, as captured in the following email: 
Everything is different compared to Greece and I seem to have some difficulties with life here... It all seems Greek to me as they say!!! September 29

The sense of helplessness that is caused by disorientation (Giddens 1991) is shown in the account offered by Kiana, which typifies the sentiments expressed by many students in the first few weeks of the sojourn:

How can I go to city or that place? I didn't know about the map. So two times I lost in the town centre. You know you didn't know anything! Nothing! What can you do, you have to wait and get used.

As Storti (1990) points out, it is the simple day-to-day activities such as shopping or catching a bus that can make the sojourner feel disoriented, as reflected in the widespread difficulty faced in working out the transport system in the host town, as commented on by Mohamed:

At first it was awful because I didn't know anything, everything is a shock, the buses, the taxis, the times, everything. Your mind is confused.

Of greater concern to interviewees however was the sense that they didn't know how to behave in everyday situations or how to interpret others' behaviour, without which skills intercultural mistakes commonly arise (Detweiler 1975):

When you go to new country, you know, you have to respect to something, but when you don't know anything, how you can respect something? It takes a long time I think. Even I didn't know how to talk to people at a bus stop. You don't know any rules. An easy 
example, let's say, you go one side on the escalator, I go on the other, I didn't know that! So then you don't know about the easiest subjects. Kiana

Successful communication relies on knowledge of appropriate guidelines for behaviour (Schild 1962), which students felt was deficient, reflected in frequent exclamations of 'I don't know what to do!' with reference to a myriad of phenomena: how to queue, how to address tutors, how to engage in small talk, how close to stand to people, how to read emotion. Being unable to communicate with ease led to a feeling of childlike vulnerability and ineptitude, which is commonly experienced early on in the stay (Kim 1988), as students felt they had to learn how to do the smallest of things all over again:

It was really difficult because oh my god, different culture, different everything and you feel like a kid! You don't know anything!

Awareness of the possibility of making intercultural mistakes is necessary until adjustment is reached (Kim 1988), and indeed, a strategy of observation of local rules of behaviour is typical of the initial stage in the sojourn (Liu 2001), followed by many students until they felt at ease in the new setting.

\section{Feeling excited}

The notion that the first stage of the sojourn is characterised by a sensation of excitement was upheld in this study as interviewees described themselves as being excited about many different aspects of the sojourn. For example, Antonio was determined to gain as much as possible from 
the sojourn, and to enjoy, not be distressed by, the thrill of the new, including such banalities as filling his car with petrol himself, listening to Radio 4 and riding on a train:

I was enjoying every minute of it. I was enjoying everything that happened, everything that I saw, you know the buildings, the people, the cars, shops, everything! I like the fact that you have shops in the street. It's not very common now in Brazil, we have shopping centres everywhere, and we don't have main streets like you do. I love it. I found it great. I had never travelled on a train like you have here. We have trains in Brazil but they are just like the underground, nothing like here, so comfortable, with a trolley and food and restaurant and toilets inside. So it was a great feeling, I felt 'oh it's cool, the train is so fast.'

Antonio thus found himself in a heightened state of awareness, which tends to describe the initial stage of the sojourn (Kim 1988). Similarly, Kyoung felt privileged to be allowed to fulfil her long-held but, as a woman, distant dream to further her education abroad:

Usually in Korea, the women have difficulty to promote or get better choice. Many Korean people would like to go abroad because of the benefits, but women cannot get that kind of opportunity, always women they apply but they fail, fail, fail!

In addition, the sojourn offered Kyoung the exhilarating opportunity to leave, albeit temporarily, the constraining domestic role she assumed at home: it was thus significant in terms of the chance it offered her as a woman to develop herself educationally and personally, reflecting Bowl's allusion (2003) to Higher Education as a major life change for women. Meanwhile, like many of the younger students, whose life plan was as yet uncharted, Paranee was both nervous and excited 
about what the future might bring, alluding to the sojourn as a journey whose outcome was unknown:

On the plane, I felt like 'am I making the right decision? What I'm going to face after this?' It's like, umm, another adventure for me! What is my destination, or something like that. Exciting in one way and question mark all the time.

Like Ward et al (2001), Paranee conceptualised the academic sojourn as a life-changing event. For students whose destiny had been fixed in the home country, this induced simultaneous feelings of both wonder and apprehension.

The international make-up of the course had a significant impact on students' state of mind, providing the consolation of solidarity in hardship in the first few weeks, and the unique and exciting chance to mix with a wide range of nationalities, that would probably not come their way again:

It's great, I never seen so many different nationalities before! So many Chinese, Thai, Indonesian! I like meeting other nationalities; I always like this international contact. Natalia

Early enthusiasm for cross-national interaction was prevalent: rightly linked with improved employability and personal growth (Westwood and Barker 1999), all interviewees recognised this as a secondary benefit of the Masters course. The unanimous willingness to improve their cultural knowledge indicates the potential of the international sojourn to lead to the creation of the intercultural mediator, who, by virtue of their cultural skills, acts as a bridge between cultures (Gudykunst 1998). 
Another source of pleasure was the physical environment of the host town; interviewees were emphatic in their praise of the greenness of the landscape, the prevalence of trees, fresh air and physical space, the lack of air pollution and of crowds, and the ability to use walking not just as a pleasurable activity but also as a means of transport, as expressed by Xia:

The countryside is very beautiful and totally different from Taiwan. We didn't have so many grasses and hills. I saw the cows and sheep, we don't have so many, it's just like a picture on the wall. And the air is clean, here you can benefit from walking on the street. I think I will lose some kilos!

In addition, favourable comparisons were drawn between this less crowded environment and the bustling cities that most had come from, with an association made between urban density and stress. An aesthetically pleasing environment, defined by Milligan et al. (2004) as a therapeutic landscape, was therefore associated by many with physical and emotional well-being. As Tunstall et al. (2004) state, place and people are inseparable, as the physical fabric of a place is a major determinant in the physical health of people. The positive reactions of interviewees to the physical environment must have been influenced to a large part by the location and situation of the host town, and it must be acknowledged that a different reaction would have obtained had students found themselves in a big industrial city such as London or Manchester. While architecture and urban layout might be strikingly different, given the influence of culture on urban planning (Hall 1976), these cities may well be less aesthetically pleasing than a small Southern English town.

\section{Dissatisfaction with aspects of life in the new country}


As noted in the models of adjustment, dissatisfaction with the host country is prevalent, sometimes leading to hostility, but often abating, with the passage of time (Oberg 1960). In this study, a source of dismay for all interviewees was the expense of the course and of the UK in comparison with their country. Pre-arrival information on cost of living is a vital pre-requisite for proper preparation for the sojourn (Torbiorn 1994). However, such information cannot completely offset the shock of confrontation with high local prices:

It's very expensive compared to the living standard in China because the weekly rent here is enough to live in China for one whole month.. I knew that it's very expensive so I save four years. Almost everything is expensive. Food, transport, the rent, bills. Ning

The importance of the weather to international students is well discussed (e.g. Okorocha 1996), and was mentioned in the final interview as one of the key obstacles to adjustment in the initial stage. To describe the weather, the adjectives most commonly used were: cold, wet, windy, irritating, freezing, uncomfortable, bothersome, disoriented and unpredictable, and the following comment by Rini was typical:

I feel the wind, and the rain! Oh my god. And the wind! Ahhh!, I think now it's colder cos of the rain and the wind. I cannot stand the rain and the wind.

The link between physical and emotional equilibrium is revealed in students’ exclamatory and emotive speech: their reaction to perceived harsh weather was shock and minimal outdoor activity, until they understood the length of the winter season. The frequency of physical illness was also attributed to the coldness of the British climate, and was associated with increased homesickness and a diminished ability to concentrate, as noted in Okorocha’s (1996) study of 
international students’ adjustment. For those from Germany, Slovenia, Russia and Korea, the British weather posed no problem because of similarity or improved weather to the home country, reflecting the positive correlation between cultural dissimilarity and distress: the more similar the culture and conditions in the host country to the origin country, the less acculturative stress will be suffered (Ward and Kennedy 1996).

British drinking behaviour was another theme of conversation and cause for hostility in the first and subsequent interviews. If culture is what is observable to visitors, reflecting a society's values (Williams, 1981), then the conclusion quickly drawn on British culture was encapsulated in Antonio’s observation that:

People drink much more here. Girls like drinking a lot, and falling on the floor, and you know, in the streets, and standing up and walking as if nothing had happened. It's so strange; you wouldn't see that in Brazil. If you speak to people from different countries and they know somebody who came to England, they would tell you that people drink a lot.

British students are widely perceived by international students as heavy drinkers (UKCOSA 2004), and according to the Tysome (2003), awareness of discrepancies in the practice and tolerance of heavy drinking is forcing many universities to rethink their approach to campus life. Unlike the previous areas of dissatisfaction, dislike of the drinking behaviour of the locals, and its association with aggression, continued to be a source of concern for all students, likened by Antonio to a British disease.

\section{Feeling depressed}


It is often suggested that it is common for sojourners to become depressed in the new country (Kim 1988), and indeed feelings of depression, variously described as down, depressed, fed-up or sad, were confessed to by many students in the first interview. As we might expect, students attributed their low mood to different factors, which were not always related to the sojourn. Antonio said for example that he was finding it hard to cope with the end of a relationship that had taken place before his departure:

(Sighing) I need something to cheer up a bit because (sighing) I've been feeling a bit down lately, for lots of reasons. (Hesitating and sighing) The problem is (sighing); it's just something personal I think more than anything else. (Sighing) I get a little depressed. Physically I feel very good. It's just emotionally that I feel a bit.... (Sighing and silence)

Struggling with the loss of a relationship at the same time as facing intense loneliness in a new culture put a strain on Antonio that was a clear illustration of how the sojourn has the capacity to push sojourners to breaking point (Berry 1994). This was encapsulated in Kiana's allusion to the sojourn as a test of endurance that she felt she might at times fail:

This is my life, my fate. What can you do? I don't know how I am still standing! Relating her mood to despair over the state of Iran and to her life as a Muslim in a western country revealed that triggers for depression are not always located in the host culture. This was not the case for Ning however, who was demoralised by her terrible,terrible encounter with an unexpected and upsetting case of discrimination on the part of a British lecturer in induction week. This incident had a severe impact on Ning's happiness level, which had previously been intact: given the link between collective identity and self-esteem, this was to be expected (Crockeer and Luhtanen 1990). 
Yeh (1976) and Golden (1973) state that it is important to distinguish between pathological illness and symptoms associated with transition: those with a history of personality problems predeparture may be more vulnerable to stress; the sojourn may exacerbate pre-existing problems. In reference to this study, depression in students was sometimes clearly caused by transition, and sometimes it was a predisposition towards feeling low that being away from home had triggered or intensified. Individual personality is important to the experience of adjustment, so that the same triggers manifest in sojourners in different ways (Berry 1994).

\section{Longing for home}

Homesickness, defined as an emotional reaction to a loss of reinforcements from the original culture (Adler 1975), is a well-documented feature of transition (Kim 1988), and was evidenced in this study in the fact that most students cried in the first interview out of homesickness, and/or talked about having cried in the first few weeks. Grief and transition are often interlinked: GarzaGuerro (1974) describes the longing sojourners experience as mourning for the 'love objects' left behind. Such mourning was evidenced in this study, particularly among married students who were intensely nostalgic about the family role they had inhabited at home. Homesickness was compounded by isolation for those, like Kiana, who lived as a single parent:

She miss her dad. And I miss him. I really need him.

Homesickness was also intensified among those who worried about people left behind in the home country: Masters students are usually older than undergraduates (Gudykunst 1998; MacLeod 2006), which means that dependents are often a source of concern (Merrill 1999), as poignantly expressed by Kiana: 
I'm sure he feel sad, he miss for us, and he said to me, 'you lost just me but I lost two persons, my wife and my daughter.' So he really missing us, it's a bad situation at the moment.

Although Mason (2002) advises qualitative researchers not to distress vulnerable participants, these interviews seemed to be cathartic and provide an outlet for the distress.

\section{Feeling lonely}

According to Owie (1982), loneliness is intertwined with transition, therefore it was understandably mentioned often by students in Interview 1, as shown in the following poignant statements:

During the night, I have time, but what I have to do? What I can to do? Nothing, so I have to stay home, watch TV, sometimes I buy a drink. But by yourself it's not really enjoyable. I have no friend at the moment, just I say hello to everybody. I want to say I have a friend in university, but I don't. Kiana

Most important to me I've got no friend here. Loneliness is around me all the time. Every night I just think of the same question - go back or not? Chinese student, October 2

Loneliness is a feeling of the realisation of a lack of meaningful contacts with others and a lack or loss of companionship (Berg 1981), resulting sometimes in physical and mental illness (Furnham 1997). Friendship networks help to ease loneliness during the initial phase of the adaptation process (Hamburg and Adams 1967; Persaud 1993), but as Antonio honestly said: 
It is not easy to make meaningful friendships, not very easy, not at all. I wish it were, but it's not. International students tend to ease their loneliness by creating a conational friendship network, (Furnham and Erdman 1995; Ward 2001), as this study found. However, for those who were the sole nationality in the cohort, loneliness was an enduring feature of the sojourn, contrasting the support and security obtained at home. According to Triandis et al. (1988), anomie is endemic in individualist society, and was a shock for those students from cultures where their social network is tight and supportive (Wheeler et al. 1989).

\section{Stress and sleeplessness}

Perhaps the source of most discomfort was the stress, a word used repeatedly by nearly all students, induced by the academic demands of the masters course they had just started. Stress is a physiological and psychological reaction to confrontation with an alien system which requires the individual to learn new and unlearn old repertoires of behaviour (Berry, 1994); it is a symptom of the struggle to regain internal equilibrium (Kim, 1988). Stress was manifested in various ways, including loss of appetite, insomnia, nervousness and tearfulness. Words used to describe how they felt about the course include: worried, nervous, scared, afraid, tough, pressured, tiring, hard and demanding. The following complaint from Paranee was typical:

Sometimes I cannot sleep and when I want to sleep I get up so early, I don't know why. I don't get up, I just try to lie on my bed, one hour later, I give up, I get up. Too much work! 
The feeling of panic expressed by this student and the desperate need for direction were widespread in the first few weeks of term, revealed in a constant stream of emails and office visits: a common refrain was the cry I am so scared! The emotional component of learning, that is the fear of failure and consequent loss of self-esteem, was revealed time and again, as Kiana's emotional exclamation reveals:

At the moment the only thing I have is the courses. Nothing else. I can't sleep, maybe 2 or 3 hours a night. I try to sleep but I can't, just think. And I wake up every day very early, 5, 4.30. I lie in bed. I feel so nervous! I think this January will kill me, so many essays. I think before I was 31 year old but now I am 41 year old, really. Just smoking, nothing more. Don't mind if I lose all my weight I don't mind. Sometimes I forget to eat. I try to eat but I can't. I feel nervous more than tired, I'm not really tired, just am worry about my result.

Whilst such apprehension is also present among home students (Sazberger-Wittenber et al. 1983), this is intensified for students who are challenged by unfamiliar academic norms and a foreign language (Blue 1993). Academic workload is a major concern for international students (Ryan and Carroll 2005): indeed, Blue (1991) claims that the academic task is more important to students than sociocultural adjustment, understandably so given that the aim of the sojourn is to gain an academic qualification (Ward et al. 2001). 


\section{Conclusion}

This study does not support the notion that the initial stage of the sojourn is characterised by euphoria (in this research this refers to the first 4 weeks of the academic sojourn, when an interview with 13 students and observation of the entire cohort had taken place). Instead, supporting observations made by Biddle (1979); and Ward (2001), it was found that stress was at its most intense at the beginning of the stay, a stage marked by the experience of the symptoms of culture shock that according to various models of adjustment characterise the second stage.

Feelings of excitement were experienced in relation to different aspects of students' new life, but these were far outweighed by the more negative mood states of anxiety, depression, loneliness and stress. Symptoms attributed to mental ill-health triggered by the academic sojourn were experienced by nearly all interviewees, reinforcing the link often made between the move to a new environment and psychological, emotional and physical disturbance (La Barre 1968; Detweiler 1975; Gudykunst 1998; Ward 2001; Ryan 2005).

The purpose of the research was to discover more about the journey that international students make when they move to a new country. Having grasped the extent of the suffering that can take place in the initial stage of the sojourn, one becomes more than ever aware of the support they need at the beginning of the sojourn. Understanding the adjustment process is an important component of the support services offered to international students. If, as this paper indicates, sojourners suffer most stress at the beginning of their stay, it follows that this is when most support should be made available. It is often claimed that ethnography can influence policy and further change (Brewer 2000), and it is hoped that this study will realise this potential by improving understanding of international students’ initial experience of the international 
academic sojourn. The discomfort confessed by international students in this and other studies also offers a glimpse into the experience of life in a new country for other international sojourners such as economic migrants, asylum seekers and refugees who do not enjoy the temporary status of the international student (Crano and Crano 1993): though not the remit of this paper, such insight could inform the content and timing of support to be offered to such sojourners.

Using the distinction made by Searle and Ward (1990) and Furnham and Erdmann (1995) between psychological and sociocultural adjustment will help to determine the intervention strategies that would best help to alleviate the symptoms of culture shock in international students. Some strategies will focus on the acquisition in students of appropriate sociocultural skills whilst others will stress the alleviation of symptoms caused by their removal from the home world, such as homesickness and loneliness. What the following interventionist strategies have in common is their timing; support should be available upon (and sometimes before) arrival:

* An informational approach can be useful in offsetting some symptoms of culture shock: prearrival information is now offered to applicants via a programme-dedicated website, providing information on study skills, the relevant programme, access to staff by email and links to a range of university services.

* The presence of International Office staff at the airport on the day of arrival would help to alleviate feelings of disorientation. This approach is vindicated in the use by tour operators of a welcoming party at foreign airports for package tourists; 
* Academic support classes should start at the beginning of term to provide students with the necessary academic skills that will help to offset the stress caused by the academic aspect of the sojourn;

* The cultivation of awareness in academic and administrative staff of the painful journey undertaken by most international students will improve their both their empathy and their responsiveness to signs of distress and requests for help, thereby alleviating students' sense of isolation;

* University services such as Counselling and Chaplaincy must be prepared to respond to international students within the first weeks of term when their need is highest. An introduction to such services during induction week would raise awareness of support and reduce students’ reluctance to seek help. Sessions may take a cultural learning approach to facilitate adjustment to everyday life or staff may adopt a therapeutic approach to lessen students' sense of loss: this depends on the symptoms students present;

* Grief for home is alleviated by social contact: this could take the form of regular social gatherings, which should be organised at department level so that students enjoy a sense of belonging. 


\section{References}

Adler, P. (1975) The transitional experience: an alternative view of culture shock Journal of Humanistic Psychology, 15, 3, 13-23

Allen, A. and Higgins, T. (1994) Higher education: the international student experience HEIST in association with UCAS

Berry, J. (1994) Acculturation and psychological adaptation: an overview In: Bouvy, A-M.; van de Vijver, F.; Boski, P. and Schmitz, P. Eds. Journeys into cross-cultural psychology Amsterdam, S\&Z

Biddle, B. (1979) Role theory: expectations, identities, and behaviors New York, Academic

Press

Blue, G. (1991) Language learning within academic constraints

In:. Adams, P.; Heaton, B.; Howarth, A. Eds. Socio-cultural issues in English for Academic Purposes Vol.

1, 2 London, Macmillan

Blue, G. (1993) Nothing succeeds like linguistic competence: the role of language in academic success In: Blue, G. Ed. Language, learning and success: studying through English Vol. 3, 1

London, Macmillan

Bock, P. (1970) Culture shock New York, Alfred Knopf

Bowl, M. (2003) Non-traditional entrants to Higher Education: they talk about people like me Stoke on Trent, Trentham

Brewer, J. (2000) Ethnography Buckingham, OUP

Brown, H.D. (1980) The optimal distance model of second language acquisition TESOL Quarterly, 14, 2, 157-164

Bruner, J. (1956) On perceptual readiness Psychological Review, 64, 2, 123-152

Church, A. (1982) Sojourner adjustment Psychological Bulletin, 91, 3, 540-572

Crano, S. and Crano, W. 1993 A measure of adjustment strain in international students Journal of Cross-cultural Psychology, 24, 3, 267-283

Crocker, J. and Luhtanen, R. (1990) Collective self-esteem and in-group bias Journal of Personality and Social Psychology, 58, 1, 60-67

Daymon, C. and Holloway, I. ～(2002) Qualitative research methods in Public Relations and Marketing Communications. London: Routledge

Detweiler, R. (1975) On inferring the intentions of a person from another culture Journal of Personality, 42, 591-611

Fetterman, D. (1998) Ethnography London: Sage

Furnham, A. (1995) Psychological and socio-cultural variables as predictors of adjustment in crosscultural transitions Psychologia, 38, 238-251 
Furnham, A. and Bochner, S. ～(1986) Culture shock New York, Methuen

Furnham, A. and Erdmann, S. (1995) Psychological and sociocultural variables as predictors of adjustment in cross-cultural transitions Psychologia, 38, 238-251

Garza-Guerrero, A. (1974) Culture shock: its mourning and the vicissitudes of identity Journal of the American Psychoanalytic Association, 22, 408-429

Giddens, A. (1991) Modernity and self-identity: self and society in the late modern age. Cambridge:

Blackwell

Golden, J. (1973) Student adjustment abroad: a psychiatrist's view International Education and cultural exchange, 8, 28-36

Gudykunst, W. (1998) Bridging differences: effective intergroup communication. London: Sage

Gullahorn, J. and Gullahorn, J. (1960) The role of the academic man as a cross-cultural mediator American Sociological Review, 25, 3, 414-417

Hall, E. (1959) The silent language. $\quad$ New York: Doubleday

Hall, E. (1976) Beyond culture New York, DoubleDay

Hamburg, D. and Adams, J. ～(1967) A perspective on coping behaviour: seeking and utilising information in major transitions. $\quad$ Archives of General Psychiatry, 17, 277-284

Hammersley, M. and Atkinson, P. (1995) Ethnography Principles in practice.

London: Tavistock Publications

Hofstede, G. (1991) Cultures and organisation: software of the mind. London: HarperCollins

Kim, Y. (1988) Communication and cross-cultural adaptation. Clevedon: Multilingual

Matters

Kramsch, C. (1993) Context and culture in language teaching Oxford, OUP

$1968 \quad$ Personality from a psychoanalytic viewpoint $\quad$ In: Norbeck, E.; Price-

Williams, D.; McCord, W. Eds. The study of personality New York, Holt, Rinehart and Winston

Liu, M-C. (2001) The adaptation and experience of foreign-born faculty members in the US

The Claremont Graduate University

Lord, P. and Dawson, C. (2002) The Induction needs of international students at postgraduate level.

London: TVU

Louie, K. (2005) Gathering cultural knowledge: useful or use with care?

In: Carroll, J. and Ryan, J. Teaching international students Abingdon: Routledge

Lysgaard, S. (1955) Adjustment in a foreign society: Norwegian Fulbright grantees visiting the United States International Social Science Bulletin, 7, 45-51

MacLeod, D. (2006) International rescue The Guardian April 18,

Mason, J. $\quad$ (2002) Qualitative researching. London: Sage 
Merrill, B. (1999) Gender, change and identity: mature women students in universities

Aldershot, Ashgate

Milligan, C., Gatrell, A.C., \& Bingley, A.F. (2004) Cultivating health: therapeutic landscapes and older people in Northern England, Social Science and Medicine, 58:2

Mohamed, O. (1997) Counselling for excellence: adjustment development of Southeast Asian students In: McNamara, D. and Harris, R. Eds. Overseas students in HE: issues in teaching and learning London, Routledge

Oberg, K. (1960) Cultural shock: adjustment to new cultural environments. Practical Anthropology,. 7, 177-82

Okorocha, E. (1996) The international student experience. Journal of Graduate Education, 2, 3, 80-84

Owie, I.

(1982) Social alienation among foreign students C College Student Journal, 16, 2,

$163-165$

Persaud, R. (1993) The loneliness of the long-distance student. Journal of International Education 4, 1, 45-51

Ryan, J. (2005) The student experience In: Carroll, J. and Ryan, J. Teaching international students Abingdon: Routledge

Ryan, J. and Carroll, J. (2005) Canaries in the coalmine: international students in Western universities In: Carroll, J. and Ryan, J. Teaching international students Abingdon: Routledge

Sazberger-Wittenber, I.,Henry, G. and Osborne, E. (1983) The Emotional experience of learning and teaching London, Routledge

Schild, E. (1962) The foreign student, as stranger, learning the norms of the host culture Journal of Social Issues, 18, 1, 41-54

Searle, W. and Ward, C. (1990) The prediction of psychological and sociocultural adjustment during cross-cultural transitions International Journal of Intercultural Relations, 14, 449-464

Smith, A (2006) Improve student experience, Rammell warns $\quad$ The Guardian, March 23

Spradley, J. (1979) The ethnographic interview. New York: Holt, Rinehart and Winston

Storti, C. (1990) The art of crossing cultures. Maine: Intercultural Press

Thomas, K. and Harrell, T. (1994) Counselling student sojourners: revisiting the U-curve of adjustment In: Althen, G. Ed .Learning across cultures New York, NAFSA

Torbiorn, I. (1994) Dynamics of cross-cultural adaptation In: Althen, G. Ed .Learning across cultures New York, NAFSA

Triandis, H.; Bontempo, R. and Villareal, M. cultural perspectives on self-ingroup relationships 323-338
(1988) Individualism and collectivism: crossJournal of Personality and Social Psychology, 54, 2, 
Tunstall, H. V. Z., Shaw, M., Dorling, D. (2004) Places and health. Journal of Epidemiological Community Health, 58, 6-10

Tysome, T. (2003) Campuses adapt to overseas influx Times Higher, Jan. 24, p. 15

UKCOSA (2004) Broadening our horizons London, UKCOSA

UKCOSA (2006) Student statistics

Available from: http://www.ukcosa.org.uk/student statistics

Ward, C.; Bochner, S.; Furnham, A. ～(2001) The psychology of culture shock. Hove:

Routledge

Ward, C. and Kennedy, A. (1996) Crossing cultures: the relationship between psychological and sociocultural dimensions of cross-cultural adjustment In J. Pandey, D. Sinha, \& D.P.S. Bhawuk (Eds.), Asian contributions to cross-cultural psychology New Delhi: Sage

Ward, C. and Kennedy, A. (1999) The measurement of socio-cultural adaptation International Journal of Intercultural Relations, 23, 4, 659-677

Westwood, M. and Barker, M. (1990) Academic achievement and social adaptation among international students: a comparison groups study of the peer-pairing program International Journal of Intercultural Relations, 14, 251-263

Wheeler, L.; Reis, H.; Bond, M. ～(1989) Collectivism-individualism in everyday social life: the Middle Kingdom and the melting pot Journal of Personality and Social Psychology, 57, 1, 79-86

Williams, R. (1981) Culture Glasgow, Fontana

Yeh, E. (1976) Cross-cultural adaptation and personal growth: the case of Chinese students Acta Pschologica Taiwanica, 18, 95-104 